\title{
Modern information technologies in the management and planning of ecologically balanced irrigation systems
}

\author{
Fyarid Abdrazakov ${ }^{1, *}$, Andrey Rukavishnikov ${ }^{2}$, Olga Miheeva ${ }^{1}$, and Denis Logashov ${ }^{1}$ \\ ${ }^{1}$ Saratov State Agrarian University named after N.I. Vavilov, Saratov, 410012, 1, Teatralnaya sq., \\ Russian Federation \\ ${ }^{2}$ Financial and Technological College of Saratov State University, 410028, 97, Michurina str., \\ Saratov, Russian Federation
}

\begin{abstract}
Canals are part of natural ecosystems, occupy a large area of reclaimed land and are an important component in obtaining guaranteed sustainable crop yields. However, the condition of the canals deteriorates over time and repairs and reconstruction of structures are necessary. The main defect of the canals is a violation of the integrity of the lining fastening. The introduction reveals the main problems and prospects of using irrigation canals. One of the most important prospects is the development of digital technologies in the field of hydraulic engineering, namely, the development of a software package that allows you to calculate the cost and rationality of a project in the shortest possible time. High-quality information exchange and planning in the conditions of agricultural production is the primary task of ecologically balanced irrigation systems. The research methodology includes the main stages of program design, as well as the basic formulas used when writing code. The results of the study include an analysis of existing programs for writing code. The program and its main functions are presented. The flowchart of the program clearly shows the algorithm of operation.
\end{abstract}

\section{Introduction}

One of the most important tasks of modern reclamation production is to improve the current state of hydraulic structures, as well as their various improvements. Scientific justification, the use of modern planning techniques, the implementation of water distribution and water use processes using the theory of optimal decision-making, methods of system analysis using the latest computing devices that ultimately optimize water, energy resources and ensure the adoption of the most effective management decisions with improved quality and technical reliability [1-3].

Irrigation systems perform the most important function in reclamation production, namely the delivery of irrigation water through the branches of the irrigation network to the irrigated areas.

\footnotetext{
*Corresponding author: abdrazakov.fk@mail.ru
} 
The current situation requires the adoption of measures for the rehabilitation and stable functioning of irrigation canals. At the same time, it is worth noting that concrete antifiltration linings become ineffective and need to be replaced, since they cannot provide the necessary minimum level of infiltration.

Canals occupy a large area of reclaimed land and are an important component in obtaining guaranteed sustainable crop yields. However, the condition of the canals deteriorates over time and repairs and reconstruction of structures are necessary. The main defect in the canals is a violation of the integrity of the lining, which leads to large losses on filtration. One of the ways to solve this problem is to use a concrete web as the main fastening material during the construction, repair and reconstruction of canals $[1,3,4,6]$.

In the period of constantly developing digital technologies, there are currently no modern programs for calculating the cost of construction and repair, which reduce the calculation time by an order of magnitude, both for production and scientific purposes. In accordance with the above, the solution of this problem will undoubtedly solve the issues of labor costs when choosing a cladding option for irrigation canals of systems [11-13].

The purpose of the study: to develop a program of technical and economic calculation of rational cladding solutions for irrigation canals.

\section{Methods}

During the research, the method of empirical cognition was used, which served as a synthesis for the theoretical analysis of literature by the deductive method. The theoretical method included abstracting, taking notes and quoting general and special scientific works of scientists in this high-tech field. Mathematical and statistical methods were used to obtain and establish quantitative dependencies between the studied phenomena. The mathematical method involved data logging. The statistical method included the determination of the average values of the obtained indicators, respectively comparing and obtaining a quantitative or qualitative dependence of the process under study

Hydraulic calculation of trapezoidal canals is carried out according to the following formulas:

When calculating canals for uniform motion, the Shezi formula is used $[1,4]$ :

$$
V=C * \sqrt{ } R * I,
$$

where $\mathrm{V}$ is the average speed of water movement in the canals, $\mathrm{m} / \mathrm{s}$;

$\mathrm{C}$ is the Shezi coefficient $\mathrm{m} 0.5 / \mathrm{s}$;

$\mathrm{R}$ is the hydraulic radius, $\mathrm{m}$

The water flow in the canals is determined from the flow formula:

$$
Q=\omega^{*} C^{*} \sqrt{ } R I
$$

where $\mathrm{Q}$ is the flow rate of water in the canals, $\mathrm{m} 3 / \mathrm{s}$;

$\omega$ is the area of the live section of the flow in the canals, $\mathrm{m} 2$

Shezi coefficient, $\mathrm{m} 0.5 / \mathrm{s}$ :

$$
C=1 / n * r y
$$

where $\mathrm{n}$ is the roughness index of the canals bed;

$\mathrm{y}$ is the exponent, $1 / 6$ is taken;

Hydraulic radius, $\mathrm{m}$ : 


$$
R=\omega / \chi
$$

where $\chi$ is the wetted perimeter, $\mathrm{m}$.

Wetted perimeter for trapezoidal

canals, m:

$$
\chi=b+2 h \sqrt{ }\left(1+m^{\wedge} 2\right)
$$

where $\mathrm{b}$ is the width of the canals along the bottom, $\mathrm{m}$;

$\mathrm{h}$ is the depth of water in the canals, $\mathrm{m}$;

$\mathrm{m}$ is the slope laying coefficient $\left(\mathrm{m}=\mathrm{ctg}^{*} \alpha\right)$

or $\chi=\mathrm{h}(\beta+2 \sqrt{ } 1+\mathrm{m} 2)$,

where $\beta$ is the relative width of the canals along the bottom $(\beta=b / h)$.

The area of the living section of the trapezoidal canals, $\mathrm{m} 2$ :

$$
\omega=h(b+m h)
$$

or with an unknown canals width along the bottom of $b$ :

$$
\omega=h 2(\beta+m)
$$

The durability of the canals mainly depends on the fastening of the bottom and slopes and on good care of them. Reinforced canals with good operation serve for an unlimited time.

With a large slope, the bottom of the canals is covered with a layer of gravel $(10 \mathrm{~cm}$ thick) or arrange fast flows of ribbed reinforced concrete slabs [7, 11].

Fixing the bottom and slopes with concrete and reinforced concrete slabs is used only in special cases: at bridges, at tubular crossings, for fastening of conducting and diverting canals of structures (pumping stations, drops, water outlets, etc.). Fastening with rubble stone is used in exceptional conditions: for the device of fast currents and strengthening of sliding slopes. The efficiency and quality of canals fastening largely depend on the timely execution of work. Advanced workers carry out this work immediately after the development of the excavation and leveling of the cavaliers. When there are no opportunities to level the cavaliers immediately after the development of the canals, a strip of at least $3 \mathrm{~m}$ wide is left between the canals and the cavalier, along which the necessary material for canal-strengthening works is brought. Every $100 \ldots 200 \mathrm{~m}$ leave lanes in the cavalier with a width of $6 \ldots 10 \mathrm{~m}$ for the entry and exit of vehicles. Fixing the bottom and slopes of the canals before leveling the cavaliers is very important in unstable soils and rainy times, when leveling the cavaliers is difficult or impossible due to the viscosity of the soil, and loose canals quickly deform. The process of fixing the bottom and slopes includes: the layout of the bottom and slopes, the device of the fence, planing, tinning $[2,3,8,10]$.

One of the new directions of fixing the bottom and slopes of the canals is the use of a concrete web. Its main advantage is the reduction of filtration from the canals bed. The web has a small surface roughness, which allows for minimal deposition of sediments along the canals route. As experiments have shown, this mount can be successfully used for fixing the bottom and slopes of canals during construction and reconstruction [1, 14].

The concrete web consists of two textile layers with a "filling" of a high-quality dry cement mixture. The layers are interconnected by textile fibers. On the inside, the canvas is covered with a layer of PVC.

The canvas bends well and easily rolls out on any surface. Its properties change dramatically after 1-2 hours after wetting with water. The cement mixture hardens, and the canvas turns into a strong layer of reinforced concrete [9]. 
Now, in order to obtain a high-strength, durable, resistant to various influences and loads coating, no mortar, mixers, formwork, shotcrete equipment is required. A roll of concrete cloth is enough.

Concrete web is widely used as a reinforcement of landslide-prone slopes, as a covering of highways, but for the first time it is used as a fastening of canals slopes in the conditions of the Saratov region.

The advantage of laying concrete in comparison with traditional methods is the high speed of laying and the possibility of its installation in all weather conditions.

A computer program was developed to calculate the required amount of concrete web. The program has a user-friendly interface and allows you to calculate the required material by entering the specified parameters.

The research methodology in sufficient form included an analysis of existing programming systems, as well as the most understandable language based on Basic and Pascal. As described above, the process of construction and reconstruction of irrigation canals includes a large number of operations, as well as a serious level of training. In an ever-evolving digital environment, manual counting and analysis is irrelevant, as it takes a lot of time. Automation of most processes of analysis and calculation of an acceptable cladding project is a primary task for modern reclamation production $[8,9]$.

The first step in creating a computer program for the technical and economic calculation of rational cladding solutions was the analysis of promising and most used materials. After that, the structure and programs were written, as well as general calculation algorithms [1, $5,6,11]$.

The second stage is the mechanical work of writing the program code, as well as its further compilation.

The third stage is testing the computer program and summing up the results.

\section{Results}

The calculation program is written in Python and represents a logical sequence of input parameters.

Python appeared in the programming world quite a long time ago, but since the beginning of 2010 it has been experiencing a boom - it has already overtaken C, C\#, Java and JavaScript in popularity.

The popularity of the programming language can be tracked by the dynamics of the number of tags on the most popular resource among developers - Stack Overflow. So, judging by the graph, Python's growth began in 2010, and it became rapid in 2015. While R has been on a plateau for the past few years, and many other languages are in decline. There are reasons for Python's popularity.

When writing the structure, every possible number of possible work options are taken into account, which can be automated and their cost-effectiveness and efficiency calculated. The following options are presented in this program:

Construction of a new structure and its further cladding

Reconstruction and repair of lining of irrigation canals;

When developing a program, it is necessary to focus on the end user. Since the program is narrow-profile, it is intended for a small consumer circle of people, namely:

- Reclamation enterprises;

- Researchers, teaching staff, graduate students and students.

Based on this, the program will be useful for industrial and scientific purposes. 




Fig 1. The popularity of programming languages on Stack Overflow.

Being a well-designed programming language, Python is perfect for solving everyday real-world tasks. It has the widest range of applications: as a tool for managing other and software components and for implementing independent programs. In fact, the range of roles that Python can play as a multipurpose programming language does not include only the areas of embedded devices and system programming, where memory usage restrictions and execution speed requirements are so great that the time and convenience of writing a program do not play a significant role, and you can hire programmers of any high qualification. Python has a huge number of high-quality ready-made modules distributed for free, which you can use in any part of the program. The module has already implemented many of the program details you need. Writing a program using ready-made modules can be compared with the construction of a prefabricated frame house: individual details: foundation, walls, roof, communications have already been made before you, you only need to choose the appropriate parts and put them together. Modules are connected using the import command, which is present at the beginning of each example.

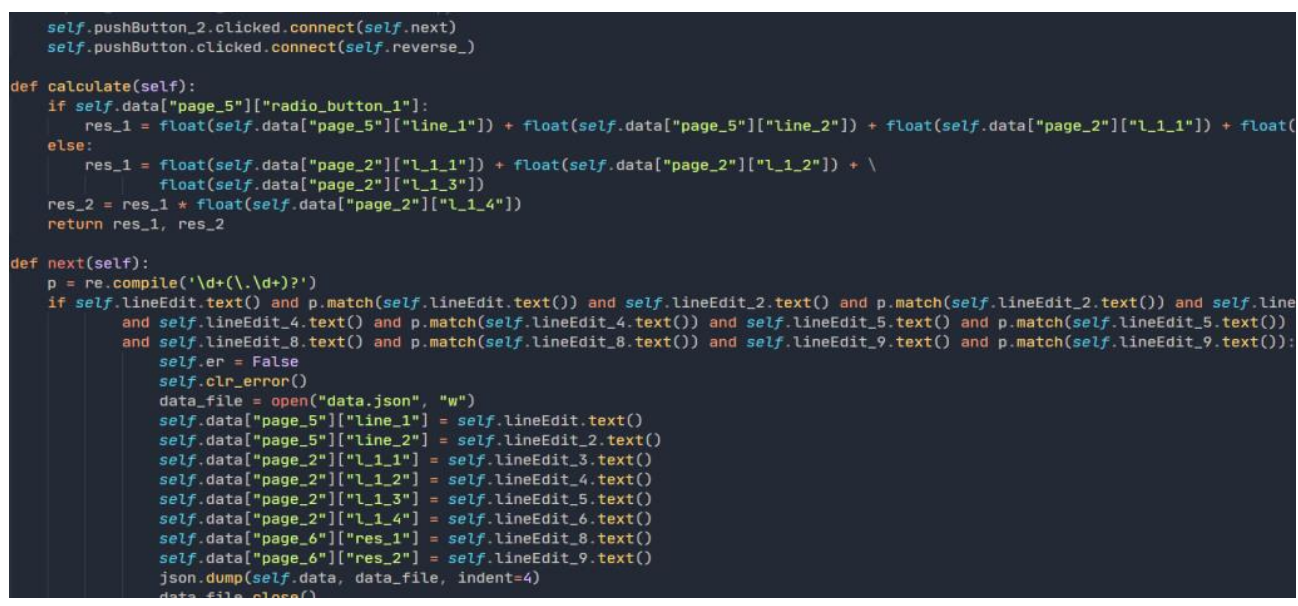

Fig. 2. Shows an excerpt of the Python program code.

The program interface is written in a graphical editor (Figure 3). This interface is userfriendly and allows you to select the data entered into the program. 


\section{Проверка параметров проекта}

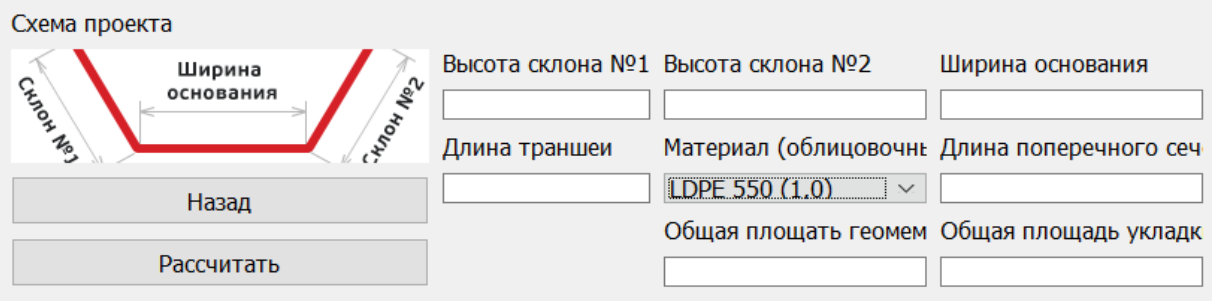

Fig. 3. Program interface for the data being driven for calculation.

The calculation program allows you to determine the cost of 1 square meter of concrete web required for fixing the bottom and slopes of the canals (Figure 4).

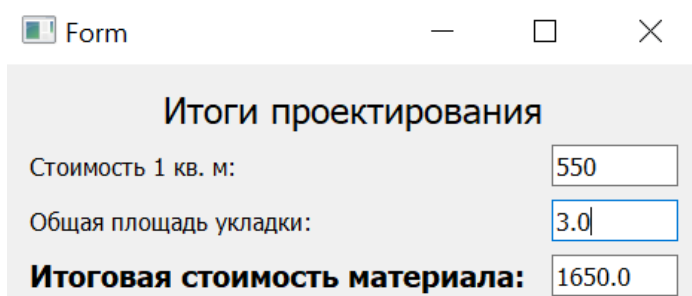

Fig. 4. Program interface for output data.

The ultimate goal was to calculate the cost of fixing the slopes and the bottom of the canals with a concrete web. The program allows you to calculate the cost of one plate, the total cost of the plates, the total cost of the tile screen, the total area of laying and additional mortar for filling joints. The final calculation is the calculation of the total cost of fastening (Figure 5).



Fig. 5. Calculation results and final cost.

Since this work was carried out in accordance with the provisions on ecologically balanced irrigation systems (ESOS) developed by I.V. Olgarenko, it can be noted that this development relates to the function of planning and management on irrigation systems [1113]. Let's present the main functions of the ESOS allocated by I.V. Olgarenko in Figure 6. 


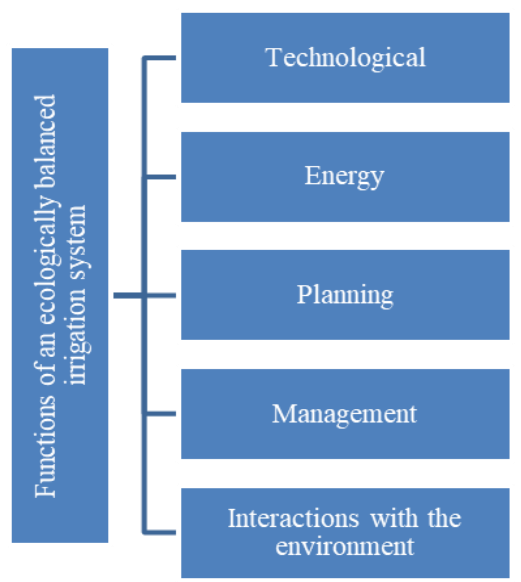

Fig. 6. Functions of an ecologically balanced irrigation system.

With all the variety of facing materials, it is necessary to choose a priority material, while the material selection algorithm can be represented as follows:

$$
X_{-}(\text {mat. })=\langle a|b| c\rangle \text {, }
$$

where $\mathrm{X}_{-}$(mat.) is the desired material; $\mathrm{a}, \mathrm{b}$ and $\mathrm{c}$ are the proposed materials.

$$
\begin{aligned}
& a=a_{i}, a_{j \ldots . . .} a_{i n,} a_{j n} \\
& a=b_{i}, b_{j \ldots . . .} b_{i n,} b_{j n} \\
& a=c_{i}, c_{j \ldots . .} c_{i n,} c_{j n}
\end{aligned}
$$

The first block of the program is used to select the intended or analyzed cladding material.

The second block of the program, as mentioned above, is the input of initial data regarding the parameters of the irrigation canals, which will be used in the calculations in the future. The calculation is based on the known initial data of the width of the bottom (c) and the length of the slopes $(a, b)$, respectively, a simple formula is used to determine:

$$
\text { Dsech. }=\mathrm{a}+\mathrm{b}+\mathrm{c} \text {, }
$$

where $\mathrm{D}$ section is the length of the cross section.

Further, the canals parameters can be calculated using the formula: $\mathrm{AB}$ (slope) $=$ $\sqrt{ }\left(\mathrm{AC}^{\wedge} 2\right)+\sqrt{ }\left(\mathrm{BC}^{\wedge} 2\right)$.

The program developed by us is simple and user-friendly from the point of view of the user. Working with the program can be done without its pre-installation, which makes the task easier for many PCs.

The third block of the program is aimed at specifying the brand of cladding material used and its cost, depending on the selected material. Each facing material has a brand or type of material classified according to certain characteristics, depending on this, the cost varies. The program calculates the area in square meters, regardless of the selected material, the cost is similarly calculated in rubles per square meter. 
The fourth block of the program gives the user an idea of all the parameters of the project, such as the length of the cross section, the laying area, the required amount of material depending on the selected cladding, etc.

The fifth block suggests editing any of the items and going back or accepting the project and continuing the calculation. Also, the fifth block offers to change the brand of the selected material without leaving this block.

The sixth block displays the total cost of the project and the exact number of necessary components, including the material.

The seventh block offers to finish the work or start all over again from the first block.

\section{Discussion}

The maintenance and reconstruction of the irrigation canal is an integral part of the life cycle. Accordingly, after the planned monitoring of the irrigation network, it is necessary to make a decision on the implementation of restoration measures. It is necessary to spend enough time to carry out all computational operations to calculate the cost of facing materials and individual features of the project.

The program takes into account technological features depending on the selected material and calculates the total cost, summing up.

The program developed by us is simple and user-friendly from the point of view of the user. Working with the program can be done without its pre-installation, which makes the task easier for many PCs. The proposed algorithm of the program accelerates the calculation by the method of determining rational cladding solutions for irrigation canals.

To obtain the necessary data, it is necessary to know the basic parameters of your irrigation canal (project): the width of the base, the depth of the canals, the length of the slopes, the width of the top, etc. At the same time, it is worth considering the fact that all the data may not be enough or they may not be reliable enough. To do this, we have developed 2 calculation options:

- by the width of the base and the length of the slopes;

- according to the depth of the canals, the width of the base and the width of the top.

\section{Conclusions}

Thus, we have developed a computer program for the technical and economic calculation of rational cladding solutions for irrigation canals. This program is universal and can be used both to calculate the cost of irrigation canals and other hydraulic engineering ones with lining clothing. The possibility of changing the program regarding prices, technologies and cladding materials is an additional advantage, since this program can be a good basis for any production purposes.

\section{References}

1. F. K. Abdrazakov, A. A. Rukavishnikov, O. V. Miheeva, D. V. Logashov, S. I. Churkina, M. A. Yarmashevich, International Scientific Conference: "Constructions Mechanics, Hydraulics and Water Resources Engineering", 1 (2020)

2. F. K. Abdrazakov, A.A. Rukavishnikov, Izvestiya Nizhnevolzhsky agrouniversitetskogo complex: Science and higher professional education, 60 (2020)

3. F. K. Abdrazakov, A. A. Rukavishnikov, Melioration and water management, 1 (2019) 
4. F. K. Abdrazakov, A. A. Rukavishnikov, Materials of the VIII National Scientific and Practical Conference with international participation (Saratov, Saratov State Agrarian University, 2020)

5. V.A. Volosukhin, Ya.V. Volosukhin, M.A. Bandurin, V.A. Nazarenko, 40 (Novocherkassk, Lik, 2018)

6. V. A. Volosukhin, S. I. Yevtushenko, V. E. Fedorchuk, RIOR Publishing Center (Moscow, 2016)

7. K. Inoshita, Journal of the Japanese Society ofIrrigation, Drainage and Reclamation Engineering, 4 (2011)

8. I Koji, Journal of the Japanese Society ofIrrigation, Drainage and Reclamation Engineering, 12 (2019)

9. Yu. M. Kosichenko, O. A. Baev, A. Yu. Garbuz, Bulletin of MGSU, 5 (2018)

10. D.B. Kraatz, FAO land and water development series, 1 (1977)

11. V.I. Olgarenko, I. V. Olgarenko, V.I. Olgarenko, In the world of scientific discoveries, 1 (2017)

12. V.I. Olgarenko, I.V. Olgarenko, S.D. Desyura, Scientific Journal of the Russian Research Institute of Problems of Land Reclamation, 1 (2019)

13. V. I. Olgarenko, G. V. Olgarenko, I. V. Olgarenko, Melioration and water management, 5 (2017)

14. V.R. Petrunina, O.V. Mikheeva, Materials of the VII International Scientific and Practical Conference, 7 (2020) 